\title{
Limiting Effects of Low Temperature on Growth and Spore Germination in Gibberella circinata, the Cause of Pitch Canker in Pine Species
}

\author{
A. R. Inman, S. C. Kirkpatrick, and T. R. Gordon, Department of Plant Pathology, and D. V. Shaw, Department of \\ Plant Sciences, University of California, Davis 95616
}

\begin{abstract}
Inman, A. R., Kirkpatrick, S. C., Gordon, T. R., and Shaw, D. V. 2008. Limiting effects of low temperature on growth and spore germination in Gibberella circinata, the cause of pitch canker in pine species. Plant Dis. 92:542-545.

Pitch canker, caused by Gibberella circinata (anamorph = Fusarium circinatum), causes canopy dieback and mortality in susceptible pine species in many parts of the world. Pitch canker is most problematic in areas with a relatively warm climate, suggesting a possible limitation on disease development imposed by low temperatures. To test this hypothesis, the effect of temperature on radial growth was examined in isolates of G. circinata of diverse geographic origin. All isolates grew most rapidly at $25^{\circ} \mathrm{C}$ and progressively more slowly at 20,15 , and $10^{\circ} \mathrm{C}$. Spore germination occurred most rapidly at $20^{\circ} \mathrm{C}$ and was slowest at $10^{\circ} \mathrm{C}$. To determine if the time required for spore germination might influence the likelihood of infection, the duration of wound susceptibility was examined by inoculating branches of susceptible Monterey pines (Pinus radiata). In each of six field trials, branches were wounded and then inoculated immediately or at 2 , 6, or 9 days after wounding. The results indicated that wounds inoculated immediately became infected at a significantly higher rate than those inoculated 2 days later. Thus, if low temperatures extend the time required for germination beyond this period, a reduced infection frequency would be expected. Such a limiting effect of temperature could help to explain the current distribution of pitch canker.
\end{abstract}

Additional keywords: forest pathology, tree disease
Pitch canker, caused by the fungus Gibberella circinata (anamorph $=$ Fusarium circinatum), was first identified in 1945 as a disease of pines in North Carolina (7). Pitch canker now occurs throughout the southeastern United States where it remains a chronic problem in plantations, nurseries, and seed orchards (2,3). In California, a pitch canker infestation that was first recognized in 1986 has expanded to affect 19 coastal counties (6). The most common symptom of pitch canker is dieback of branch tips resulting from girdling lesions. Severely affected trees also develop resinous cankers on large branches and the main stem, leading to extensive canopy dieback and death of the entire tree in some cases.

In California, pitch canker is found primarily near the coast where moisture in the form of rain or fog coincides with moderate temperatures (6). Limited occurrence of the disease in cooler areas north of San Francisco $\left(37^{\circ} 47^{\prime} \mathrm{N}\right)$ or montane locations farther inland cannot be explained by a lack of susceptible hosts. For example,

Corresponding author: T. R. Gordon

E-mail: trgordon@ucdavis.edu

Accepted for publication 9 November 2007.

doi:10.1094/PDIS-92-4-0542

(C) 2008 The American Phytopathological Society many species common in the Sierra $\mathrm{Ne}$ vada foothills are susceptible to pitch canker, including Pinus ponderosa, $P$. sabiniana, and $P$. coulteri (6). The pitch canker pathogen was discovered in the Sierra Nevada (El Dorado County) on Douglas-fir (Pseudotsuga menziesii) in 2003 (10), but the infestation appears to be isolated. Whether or not pitch canker becomes established in this area may depend on the extent to which environmental factors limit the ability of the pathogen to infect susceptible hosts. The current distribution of pitch canker in California sug- gests that cooler temperatures associated with northerly and montane environments may impose such a limitation.

G. circinata requires a wound to establish an infection. Wounds may be caused by insects or injuries associated with weather or silvicultural practices $(8,9)$. If germination and growth of the fungus proceed more slowly at cooler temperatures, wounded tissue may cease to be susceptible before the pathogen can establish an infection.

The principal goal of this study was to characterize the limiting effects of low temperature on growth and spore germination in $G$. circinata in vitro. To determine if these effects of temperature could influence the pathogen's ability to establish an infection under field conditions, an experiment was conducted to determine how long wounded tissue remains susceptible.

\section{MATERIALS AND METHODS}

Radial growth. This study included eight isolates of G. circinata from California, which represents most of the vegetative compatibility groups identified in this population (5), two isolates from the southeastern United States, and four from elsewhere in the world (Table 1). Each isolate was previously subcultured from a single spore and stored on dried filter paper (Whatman No. 2) at $4^{\circ} \mathrm{C}$. An experiment was initiated by removing a 4-mmdiameter core from the edge of a culture growing on potato dextrose agar (PDA) and placing it at the center of a $9-\mathrm{cm}-$ diameter plate of PDA. Two replicate
Table 1. Geographic origin of Gibberella circinata isolates used in radial growth experiments

\begin{tabular}{llll}
\hline Isolate & Geographic origin $^{\mathbf{a}}$ & VCG $^{\mathbf{b}}$ & Other isolate designation (reference) $^{\text {Oren }}$ \\
\hline GL53 & California, USA & C3 & None \\
GL54 & California, USA & C8 & None \\
GL55 & California, USA & C6 & Fsp74 (11) \\
GL56 & California, USA & C1 & None \\
GL57 & California, USA & C9 & None \\
GL58 & California, USA & C10 & None \\
GL59 & Florida, USA & SE1 & FL10 (11) \\
GL60 & South Africa & SA18 & SA0026 (11) \\
GL61 & Spain & NA d & None \\
GL62 & Mexico & M4 & A3 (11) \\
GL294 & Georgia, USA & SE4 & FK867 (4,11) \\
GL298 & Japan & C7 & SA-GE 37 (4,11) \\
GL311 & California, USA & C5 & Fsp456 (11) \\
GL312 & California, USA & C7 & None \\
\hline
\end{tabular}

${ }^{a}$ Location where the isolate was obtained.

b Vegetative compatibility group to which the isolate is assigned.

c No other designation has been used for this isolate.

d No vegetative compatibility group identified for this isolate. 
plates of each isolate were placed in each of four incubators set at $10,15,20$, or $25^{\circ} \mathrm{C}$. The accuracy of these temperature settings was confirmed by comparisons with readings from a precision thermometer (Miller and Weber Inc., New York). At three separate times after the experiment was initiated, a subset of plates was removed from each incubator for measurement of colony diameters and then discarded; each plate was used for only one measurement. Cultures that did not grow in a circular pattern were measured on perpendicular axes and the two measurements were averaged to represent the colony diameter. Measurements were taken at 6,9 , and 12 days for plates incubated at $10^{\circ} \mathrm{C}$; at 4,7 , and 10 days for plates at $15^{\circ} \mathrm{C}$; and at 2,4 , and 6 days for plates at 20 or $25^{\circ} \mathrm{C}$. This experiment was conducted twice.

Within each experiment, measurements of colony diameter obtained for each set of plates for each isolate at three time points were used to calculate growth rates by regressing colony diameter on the day of measurement. Thus, two estimates of growth rate were obtained for each isolate at each temperature in each of two experiments.

Spore germination. Spore suspensions were prepared from 5- to 7-day-old cultures grown on PDA at room temperature $\left(22 \pm 1.5^{\circ} \mathrm{C}\right)$. A glass rod was used to suspend spores in a sterile, aqueous solution of $0.5 \%$ potassium chloride $(\mathrm{KCl})$, which was filtered through four layers of cheesecloth to remove hyphae. The resulting spore suspension, which consisted of $>99 \%$ microconidia, was quantified with a hemacytometer, and thereafter, was diluted to obtain a density of 50 spores per microliter. Spore suspensions were stored at $4^{\circ} \mathrm{C}$ for as much as $2 \mathrm{~h}$ before being used. Four $1-\mu l$ drops of a spore suspension were placed on PDA approximately $2 \mathrm{~cm}$ inside the edge of 9-cm-diameter plates. These drops were spaced approximately $3 \mathrm{~cm}$ apart. Inoculated plates were placed in temperature-controlled incubators set at 10,15 , or $20^{\circ} \mathrm{C}$ and removed at either 24 or $48 \mathrm{~h}$ thereafter to quantify spore germination.

After plates were removed from an incubator, $2 \mu \mathrm{l}$ of aniline blue dye $(20 \mathrm{ml} 85 \%$ of lactic acid, $40 \mathrm{ml}$ of glycerol, $20 \mathrm{ml}$ of $\mathrm{sdH}_{2} \mathrm{O}$ and $0.1 \mathrm{~g}$ of aniline blue) were deposited onto each group of spores to visualize both germinated and nongerminated spores. Plates were stored at $4{ }^{\circ} \mathrm{C}$ until the stain was fully absorbed into the medium, after which spores were examined microscopically at $\times 400$. Spores were counted as germinated when the length of the germ tube was equal to or greater than the long dimension of the spore from which it emerged. This experiment was conducted three times.

Susceptibility of wounded tissue. These experiments were designed to deter- mine how long wounded tissue remained susceptible to infection under field conditions and they were conducted on the U.C. Davis campus using Monterey pines (Pinus radiata) that were approximately 6 years old. Four branches on each of five trees were selected for each trial. Eight wounds were made on each branch. Wounds, spaced 2.5 to $3 \mathrm{~cm}$ apart, were made by inserting a 0.3 -mm-diameter needle into a branch to a depth of approximately $1 \mathrm{~mm}$. To account for possible differences associated with tissue age, the four wounds closest to the branch tip were treated as one block (distal) and the remaining four as a second block (proximal). On the same day that wounds were made (day zero), approximately 1,000 spores in $5 \mu \mathrm{l}$ of $0.5 \% \mathrm{KCl}$ were deposited into each of two wounds on each branch, one in the proximal group and one in the distal group. The remaining wounds were inoculated in the same manner at 2, 6, and 9 days after wounding. A single isolate, GL56 (Table 1 ), found to germinate as quickly as any isolate tested at $10^{\circ} \mathrm{C}$ (data not shown), was used for all inoculations. A total of six trials were conducted, with initiation dates on 6 December 2004 and 5 January, 31 March, 18 April, 24 May, and 31 May of 2005. In all trials, an extra branch on each tree was inoculated on day zero for use in determining when wounds had become infected; i.e., when lesions were visible. This information made it possible to select
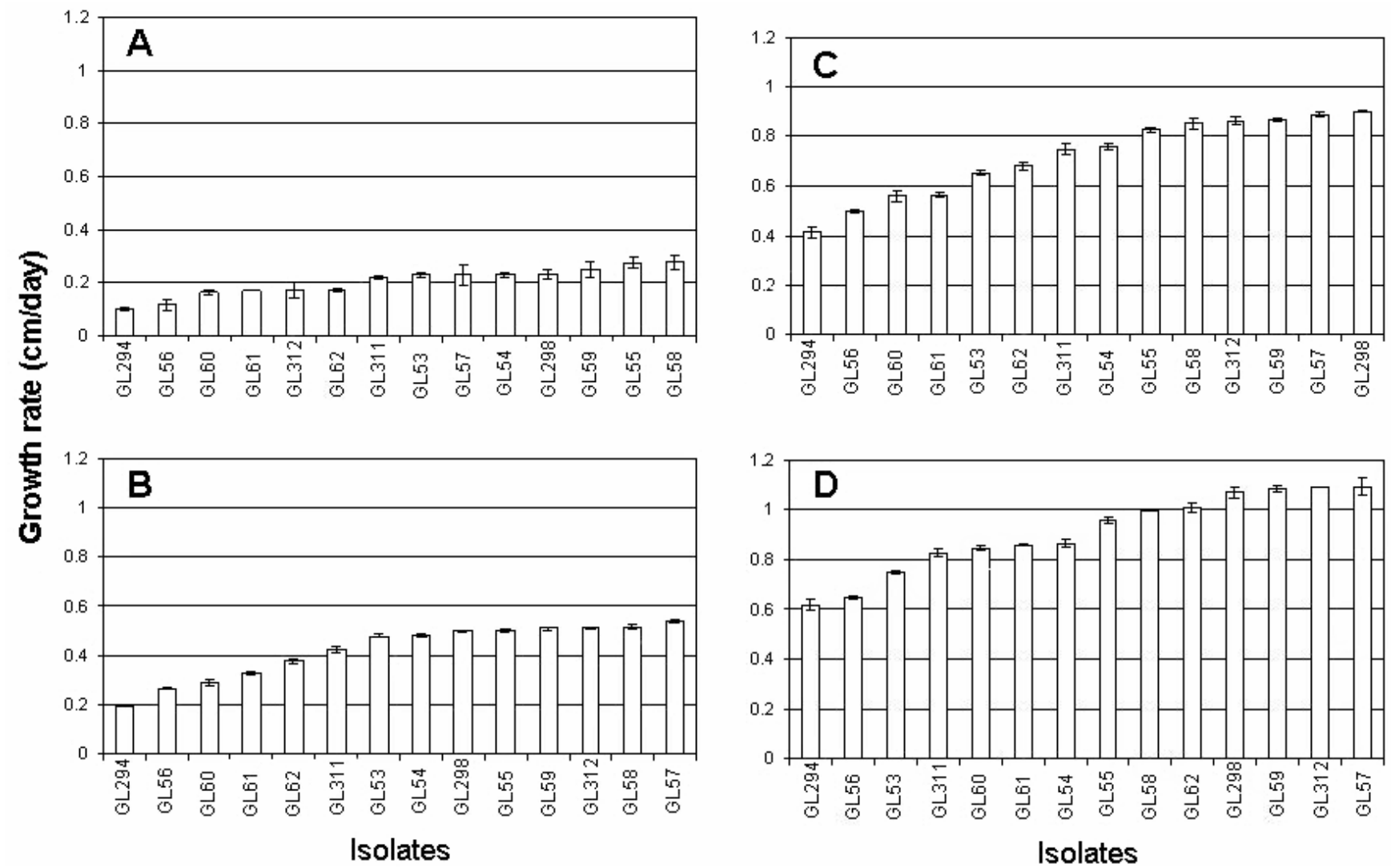

Fig. 1. Mean radial growth rates for 14 isolates of Gibberella circinata grown at 10 (A), 15 (B), 20 (C), and $25^{\circ} \mathrm{C}$ (D). Error bars correspond to $2 \times$ the standard error of the mean. 
Table 2. Analysis of fixed effects on radial growth of 14 isolates of Gibberella circinata

\begin{tabular}{lcccc}
\hline Effect & Numerator DF & Denominator DF & $\boldsymbol{F}$ value & $\boldsymbol{P}$ value \\
\hline Isolate & 13 & 39 & 14.94 & $<0.0001$ \\
Temperature & 3 & 39 & 408.11 & $<0.0001$ \\
\hline
\end{tabular}

Table 3. Analysis of fixed effects on percent germination of conidia of two isolates of Gibberella circinata after a $24-\mathrm{h}$ incubation period

\begin{tabular}{lcccc}
\hline Effect & Numerator DF & Denominator DF & $\boldsymbol{F}$ value & $\boldsymbol{P}$ value \\
\hline Isolate & 1 & 4.38 & 0.60 & 0.4790 \\
Temperature & 2 & 3 & 563.70 & $<0.0001$ \\
\hline
\end{tabular}

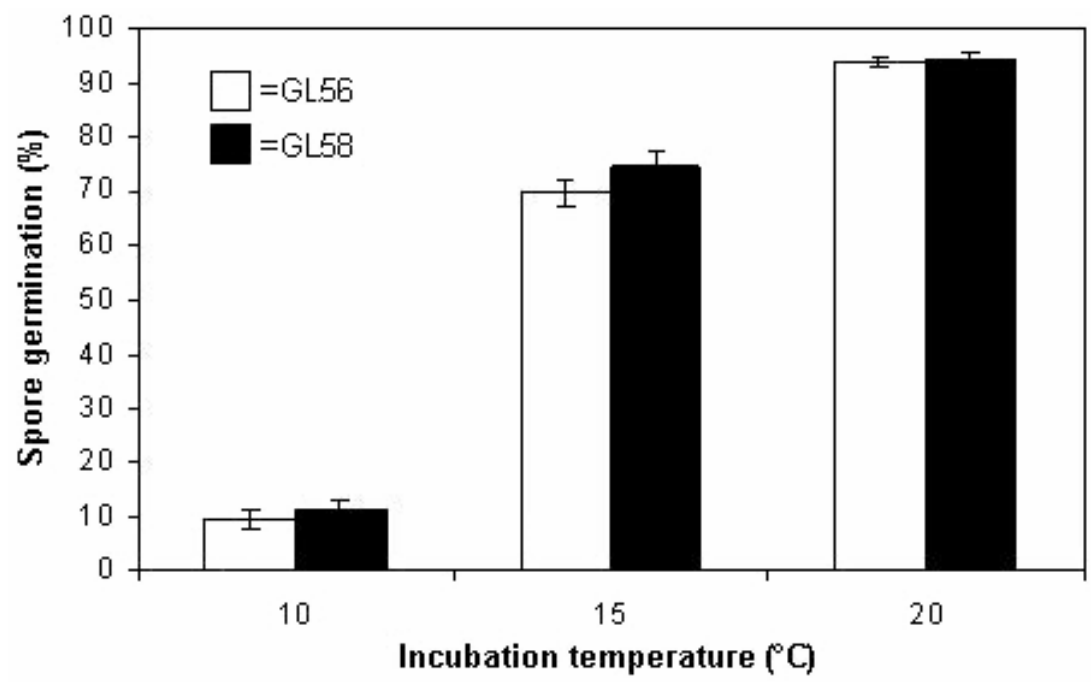

Fig. 2. Mean germination rates for two isolates of Gibberella circinata after $24 \mathrm{~h}$ at 10,15 , and $20^{\circ} \mathrm{C}$. Error bars correspond to $2 \times$ the standard error of the mean.

an appropriate date to remove experimental branches and rate wounds for infection. Accordingly, branches were harvested at either 12 (trials one and two), 8 (trials three and four), or 5 (trials five and six) weeks after the initiation date. After harvest, bark was removed and each inoculation site was scored as plus or minus for infection on the basis of presence or absence of a lesion, respectively. During each trial, temperatures were monitored with a data logger (HOBO Model H8; Onset Computer Corp., Bourne, MA) placed adjacent to trees at the experimental site.

Data analysis. SAS (release 9.1; SAS Institute, Cary, NC) was used for all analytical procedures. Linear regression (Proc Reg) was used to estimate radial growth rates from measurements of colony diameter over time by obtaining the slope of the line relating diameter to time of measurement. The significance of differences in growth rate among isolates was tested with analysis of variance (ANOVA) using Proc Mixed. In these analyses, isolate and temperature were treated as fixed effects and replication and interaction terms as random effects. The significance of random effects was evaluated with a $\chi^{2}$ test to compare residual log likelihood values obtained with and without the random term included in the model. Log transformations were used where necessary to achieve homogeneity of variances. For spore germination data, percentages were arcsin transformed prior to analyses. Data from wound susceptibility experiments were analyzed with $\chi^{2}$ tests and logistic regression (Proc Logistic).

\section{RESULTS}

Radial growth. Growth was slowest at $10^{\circ} \mathrm{C}$, with mean radial growth rates for 14 isolates ranging from 0.10 to $0.29 \mathrm{~cm} /$ day (Fig. 1A). Isolates grew progressively more rapidly at $15^{\circ} \mathrm{C}$ (Fig. 1B) and $20^{\circ} \mathrm{C}$ (Fig. 1C), with the highest growth rates, ranging from 0.62 to $1.09 \mathrm{~cm} /$ day, recorded at $25^{\circ} \mathrm{C}$ (Fig. 1D). Analysis of the full data set, following transformation $\left(\log _{10}(\right.$ growth rate +1$\left.)\right)$, revealed significant effects of isolate and temperature (Table 2) and the temperature*isolate interaction $\left(\chi^{2}\right.$ $=250.7,1 \mathrm{df}, P<0.0001)$. To gauge the relative importance of the interaction, the SAS procedure VARCOMP was used to compute variance components based on a completely randomized model. The variance component for temperature (0.00773) was nearly 30 -fold higher than for the temperature*isolate interaction (0.00026). Thus, not withstanding a highly significant $P$ value, the differential effect of temperature on the isolates tested was a relatively minor contributor to the observed variation in growth rate. Single factor ANOVAs showed differences between isolates to be highly significant at all temperatures $(P<$ 0.001 in all cases)

Spore germination. On the basis of the results of growth rate experiments and preliminary spore germination experiments (data not shown), two isolates were selected as representative of the observed variation. These two isolates, GL56 and GL58, were used to examine the effects of temperature on spore germination. Germination rates were quantified at 10,15 , and $20^{\circ} \mathrm{C}$ in each of three successive experiments, and each experiment was treated as a block in the analysis. On the basis of counts taken at $24 \mathrm{~h}$, ANOVA indicated that block*isolate and temperature*isolate interactions were not significant $\left(\chi^{2}=1.3\right.$, $1 \mathrm{df}, P=0.254$ and $\chi^{2}=0,1 \mathrm{df}, P>0.999$, respectively). The effect of temperature on spore germination was highly significant (Table 3). Mean germination rates for the two isolates were very similar (Fig. 2), and the difference, averaged across blocks and temperatures, was not significant (Table 3 ).

After $48 \mathrm{~h}$, the extent of growth of germinated spores at $20^{\circ} \mathrm{C}$ precluded making accurate counts, so comparisons were limited to the two lower temperatures. Mean germination rates ( \pm standard errors) at $15^{\circ} \mathrm{C}$ were $98.5 \pm 0.5 \%$ and $99.1 \pm 0.5 \%$ for GL56 and GL58, respectively; and were significantly lower for both isolates at $10^{\circ} \mathrm{C}: 80.1 \pm 2.4 \%$ and $81.7 \pm 2.2 \%$ for GL56 and GL58, respectively. At the 48-h time point, the effect of isolate on germination, pooled across temperatures, was not significant $(P=0.326)$, whereas the effect of temperature, pooled across isolates, was highly significant $(P=0.007)$.

Susceptibility of wounded tissue. The duration of susceptibility of wounded tissue was characterized in six field trials The proportion of wounds infected in trials one and two was too low to allow for an evaluation of branch or tree effects on infection frequency (Fig. 3). For the remaining four trials, $\chi^{2}$ tests showed that frequency of infection did not differ among individual trees $(P \geq 0.057)$, so data were pooled across trees within each trial. Similarly, $\chi^{2}$ tests showed that locations within a branch (distal versus proximal) did not differ significantly in infection frequency in trials three to six $(P \geq 0.587)$. Consequently, data were compiled as the proportion of wounds infected per branch for each day of inoculation, with branches serving as units of replication. Data were further analyzed using logistic regression, which showed both day-of-inoculation and trial to have highly significant effects on infection frequency $(P<0.0001$ in both cases). The interaction between day and trial was also significant $(P<0.0001)$, so effects of day-of-inoculation were tested within each trial separately.

The proportion of wounds infected ranged from 0.025 to 0.075 ( 3 of 40 ) in trial one and 0 to 0.10 (4 of 40) in trial two 


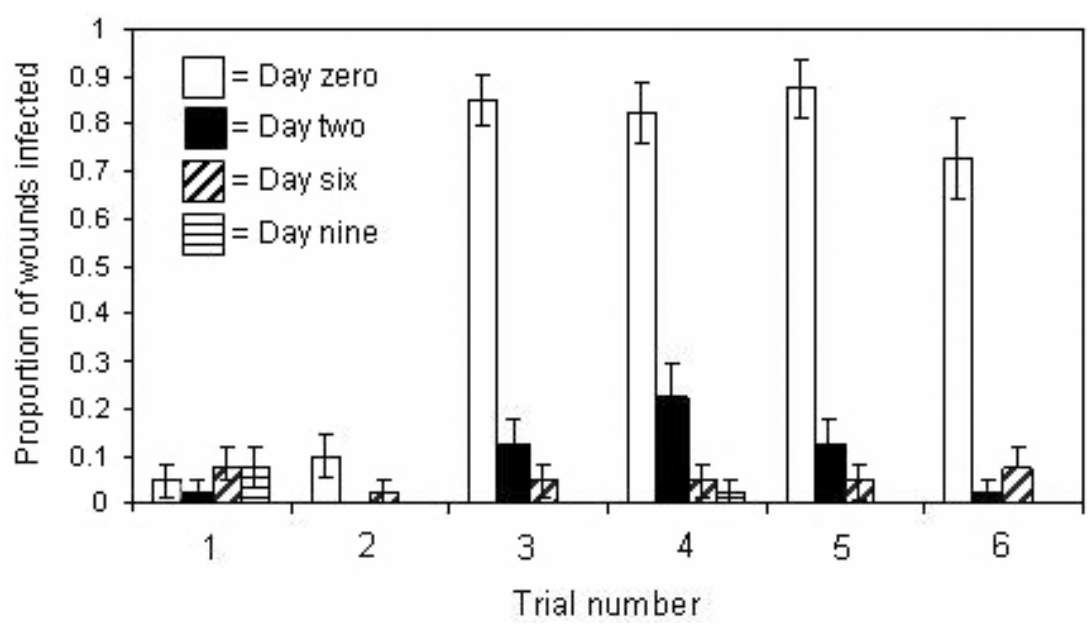

Fig. 3. Mean proportion of wounds infected when inoculated with Gibberella circinata at 0, 2, 6, or 9 days after wounds were made. Error bars represent $2 \times$ the standard error of the mean. Means are shown separately for each of six trials.

(Fig. 3), both of which were conducted during the winter. The effect of inoculation-day was not significant $(P=0.368$ and 0.134 for trials one and two, respectively). In trials three and four (conducted in the spring), the effect of inoculation-day was highly significant $(P<0.0001$ for both trials), with the highest infection frequency ( 0.85 in both trials) being recorded for day zero (Fig. 3). The results of trials five and six (initiated during the spring) were very similar to the third and fourth trials and the effect of inoculation-day was again highly significant $(P<0.0001$ in both cases $)$.

\section{DISCUSSION}

Throughout the world, pitch canker is found predominantly in areas with relatively warm climates, suggesting that the distribution of the disease may be influenced by ambient temperatures. In California, the northern limit of the pitch canker infestation is in Mendocino County at approximately $39^{\circ} \mathrm{N}$ latitude. The absence of pitch canker in stands of susceptible species (Monterey and Bishop pines) north of this location suggests that environmental conditions might constitute a barrier to northward expansion of the pitch canker infestation in coastal California. In particular, relatively cool temperatures during periods when moisture is available may limit the frequency and duration of intervals suitable for infection.

Our results show that radial growth rates of all isolates of $G$. circinata are drastically reduced as temperatures drop from 25 to $10^{\circ} \mathrm{C}$, and the percentage of spores germinating within $24 \mathrm{~h}$ is significantly lower at $10^{\circ} \mathrm{C}$ than at $15^{\circ} \mathrm{C}$. The potential importance of temperature effects on germination and growth rate is suggested by the results of wounding experiments.
These experiments document a significant decrease in infection frequency of wounded tissue within 2 days after wounding. A reduced infection rate presumably reflects host responses to wounding that inhibit germination and growth of the pathogen and/or desiccation of the exposed tissues. Regardless of the underlying cause(s), the duration of wound susceptibility imposes a limit on the time available for the fungus to establish an infection. Thus, to the extent that low temperatures extend the time required for germination beyond the interval of wound susceptibility, a corresponding reduction in infection frequency would be expected. Such an effect could explain the very low infection rates recorded on day zero in trials one and two when average temperatures during the $72 \mathrm{~h}$ following inoculations (the period likely to be determinative) were 11.1 and $7.8^{\circ} \mathrm{C}$, respectively. Temperatures for the corresponding period in trials three to six ranged from 13.1 to $24.7^{\circ} \mathrm{C}$, and day zero infection rates were $72.5 \%$ or higher. Although these results are consistent with a limiting effect of low temperatures on germination and growth of the pathogen, an indirect effect of environmental conditions mediated by the physiology of the tree may also contribute, and such an effect could not be separated from a direct effect on the fungus.

Our study revealed significant variation in isolate growth rates at all temperatures tested, including $10^{\circ} \mathrm{C}$. A significant isolate effect on germination rate was not documented, but more extensive sampling might well reveal significant variation in contemporary populations. Furthermore, $G$. circinata is capable of sexual reproduction (1) and both mating types are found in California (12). If genetic recombination does occur, natural selection for more rapid germination and growth at lower temperatures could facilitate the pathogen's adaptation to cooler conditions. The emergence of more cold-tolerant strains of $G$. circinata might ease current limitations on the geographic range of the pathogen and thereby promote development of pitch canker in the western United States and perhaps elsewhere in the world.

\section{ACKNOWLEDGMENTS}

The research described herein was supported, in part, by USDA-CSREES Exotic/Invasive Pests and Diseases Research Program grant 03XU022. The authors appreciate contributions to the completion of this work from Jeness Petersen and Chris Friel.

\section{LITERATURE CITED}

1. Britz, H., Coutinho, T. A., Wingfield, M. J., Marasas, W. F. O., Gordon, T. R., and Leslie, J. F. 1999. Fusarium subglutinans f. sp. pini represents a distinct mating population in the Gibberella fujikuroi species complex. Appl. Environ. Microbiol. 65:1198-1201.

2. Carey, W. A., Oak, S. W., and Enebak, S. A. 2005. Pitch canker ratings of longleaf pine clones correlate with Fusarium circinatum infestation of seeds and seedling mortality in containers. Forest Pathol. 35:205-212.

3. Dwinell, L. D., Barrows-Broaddus, J. B., and Kuhlman, E. G. 1985. Pitch canker: A disease complex of southern pines. Plant Dis. 69:270276.

4. Gordon, T. R., Kirkpatrick, S. C., Aegerter, B. J., Wood, D. L., and Storer, A. J. 2006. Susceptibility of Douglas-fir (Pseudotsuga menziesii) to pitch canker, caused by Gibberella circinata (anamorph $=$ Fusarium circinatum $)$. Plant Pathol. 55:231-237.

5. Gordon, T. R., Storer, A. J., and Okamoto, D. 1996. The population structure of the pitch canker pathogen, Fusarium subglutinans f. sp. pini, in California. Mycol. Res. 100:850-854.

6. Gordon, T. R., Storer, A. J., and Wood, D. L. 2001. The pitch canker epidemic in California. Plant Dis. 85:1128-1139.

7. Hepting, G. H., and Roth, E. R. 1946. Pitch Canker, a new disease of some southern pines. J. For. 44:742-744.

8. Kuhlman, E. G. 1987. Effects of inoculation treatment with Fusarium moniliforme var. subglutinans on dieback of loblolly and slash pine seedlings. Plant Dis. 71:161-162.

9. Sakamoto, J. M., and Gordon, T. R. 2006. Factors influencing infection of mechanical wounds by Fusarium circinatum on Monterey pines (Pinus radiata) Plant Pathol. 55:130136.

10. Vogler, D. R., Gordon, T. R., Aegerter, B. J., Kirkpatrick, S. C., Lunak, G. A., Stover, P., and Violett, P. 2004. First report of the pitch canker fungus (Fusarium circinatum) in the Sierra Nevada of California. Plant Dis. 88:772.

11. Wikler, K., and Gordon, T. R. 2000. An initial assessment of genetic relationships among populations of Fusarium circinatum in different parts of the world. Can. J. Bot. 78:709-717.

12. Wikler, K., Gordon, T. R., Clark, S. L., Wingfield, M. J., and Britz, H. 2000. Potential for outcrossing in an apparently asexual population of Fusarium circinatum, the causal agent of pitch canker disease. Mycologia 92:1085-1090. 